\title{
Virtual Reality as a tool to regain tactual procedures in digital design
}

\section{SIGRADI2018 TECHNOPOLITICAS \\ xxii congresso da sociedade iberoamericana de gráfica digital 22th conference of the iberoamerican society of digital graphics 07|08|09|novembro|2018 iau usp | são carlos | sp br}

\author{
Tales Lobosco \\ Lagear | UFMG | Brazil | tales@lobosco.com.br
}

\begin{abstract}
This article aims to analyze the transformations undergone in design since the implementation of the digital processes. Seeking to discuss the limits for the construction of an operational model that does not act directly on the generated form and where the gesture and the materiality lost their place. In this sense, this paper proposes a project experience based on the interaction between analogue and virtual reality tools, allowing the retrieval of tactile and material interactions, with the direct manipulation of the final shape of the object in a digital design environment.
\end{abstract}

Keywords: Digital design; Tactual; Materiality; Virtual reality; Gesture.

\section{INTRODUÇÃO}

As ferramentas de design digital em arquitetura, embora tenham despontado como uma plataforma de aperfeiçoamento das atividades representativas, ultrapassaram as atribuições originais e passaram a se incorporar cada vez mais ao processo de projetação. Este desenvolvimento culminou com a elaboração de abordagens digitais voltadas à geração e ao desenvolvimento projetual, alterando significativamente o modo de atuação dos arquitetos. Nesta lógica os arquitetos deixam de atuar diretamente sobre uma forma - definidora da configuração externa do edifício - e passam a articular parâmetros generativos - a lógica que vai produzir, de modo automático, a gama de possibilidades, da qual o arquiteto escolherá a forma final. Nesta radical transformação, as formas deixam de ser desenvolvidas a partir de representações gráficas estruturadas em planos ortogonais que organizam o espaço para se tornarem entidades calculadas a partir de parâmetros e métodos computacionais externamente definidos. A perda da primazia do plano, associada à facilidade em lidar com formas complexas e irregulares alteram o sentido de muitos dos parâmetros tradicionais de projeto, como a simetria, alinhamentos e repetição, que deixam de ditar a lógica estruturante da concepção (Kolarevic, 2003).

A evolução dos processos computacionais permitiu integrar a produção arquitetônica em um continuum digital capaz de lidar com grande quantidade de informação, garantindo a precisão no processo, desde o projeto até a execução. Este encadeamento digital alterou a lógica ortogonal e repetitiva permitindo ao projeto incorporar relações de grande complexidade e variabilidade formal. Essa transformação, porém, não veio sem um custo intrínseco: os processos de projeto se distanciaram da atuação direta sobre o artefato produzido, abandonando uma relação intuitiva e gestual, para se organizar em procedimentos excessivamente objetificados (Cabral Filho, 2013) que se amparam na variabilidade de soluções geradas para respaldar uma "escolha da forma", diante da falta de uma relação cognitiva capaz de "construir a forma".

\section{DAS FERRAMENTAS AO PROCESSO DE PROJETO DIGITAL}

As primeiras ferramentas digitais se organizaram a partir da formulação de um suporte computacional para simulação dos procedimentos de representação tradicionais, sendo, portanto, uma ferramenta de apoio ao projeto, que não visava transformar o método de trabalho, mas facilitar e aportar maior precisão às representações.

Os primeiros movimentos no sentido da elaboração de um procedimento especificamente digital de projeto podem ser identificados a partir do surgimento das propostas de arquitetura "Non-Standard" que buscava romper a lógica de modulação e padronização repetitiva associada aos processos de reprodução e industrialização seriada (Oxman, 2006). Um efeito colateral desta proposta foi colocar em evidência uma importante característica do design arquitetônico digitalmente mediado, sua capacidade de lidar com grande quantidade de informações, desde o momento da geração das formas até a efetiva produção do edifício. Este volume de informação pode ser expresso, segundo Mitchell (2005), através da complexidade formal do conjunto ou de suas partes, e da não repetitividade de seus componentes.

Através das propostas da arquitetura "Non-Standard" podemos perceber que, ainda que os processos de fabricação não fossem totalmente digitais, a capacidade de conexão e integração das informações em suporte digital ao longo de toda a cadeia produtiva e projetual, trouxe grandes transformações no resultado final das arquiteturas propostas. Entretanto, a revolução desta nova forma de design se limitava a propor alternativas significantes à lógica da repetição e à capacidade de lidar com a complexidade formal e construtiva. Certamente uma grande transformação na cultura projetual, com a 
emergência de características formais e construtivas, marcadas por grande diversidade e complexidade, mas incapazes de propor uma alteração radical na metodologia projetual (Oxman, 2006).

De acordo com Oxman (2006) o discurso apoiado em uma fundamentação teórica própria e a formulação de novos paradigmas, capazes de definir propriedades e características específicas de atuação de um modo projetual organizado através das ferramentas e suportes digitais só começam a tomar forma quando os processos de geração formal se tornam igualmente digitais. Nestas situações, a geração e a interação com as formas projetadas se diferenciam significativamente da geração e interação com a "forma livre" da representação baseada no papel.

Assim, sob o título genérico de design digital existem diferentes estratégias que variam de acordo com o grau de desenvolvimento deixado a cargo da máquina, diferenciando processos nos quais o computador é responsável pela produção de uma forma preconcebida daqueles em que ele é participante ativo no desenvolvimento da própria forma (Cabral Filho, 2013).

Os modelos de design tradicional são baseados primordialmente em relações de conhecimento implícitas, com operações de geração e avaliação não formalizadas ou associadas a critérios não objetivos como intuição e criatividade. Em um processo efetivamente digital de design, as relações cognitivas e intuitivas dão lugar a uma formulação e implementação de relações de conhecimento claramente formalizadas e objetivas. Nesta situação, os padrões de interação com o projeto se alteram de uma relação livre que atua diretamente sobre as formas propostas no papel para uma estruturada por esquemas digitais, nas quais o arquiteto organiza e implementa o conjunto de diretrizes que definem a geração formal (Oxman, 2006).

Deste modo, a modelagem paramétrica digital transformou a notação explicitamente geométrica, existente nos processos de representação digital, em relações geométricas instrumentais. Assim, a atuação dos arquitetos deixa de se debruçar prioritariamente sobre a forma específica de um edifício para deslocar sua atenção para a configuração de princípios e relações geométricas que irão determinar instâncias particulares de design como resposta às condições e parâmetros determinados (Menges, 2006).

\section{PROJETO DIGITAL, GESTO E COGNIÇÃO}

O design paramétrico permite a elaboração de uma enorme quantidade de manifestações geométricas similares que se expressam através de um esquema geométrico previamente articulado. Nesta organização, são os parâmetros numéricos, responsáveis pela formulação de variantes do esquema, que são declarados e não a configuração final do projeto. Assim, ao final do processo, são esses dados numéricos, muitas vezes abstratos, que alimentam as relações geométricas definidas pelo esquema, logo, serão eles os responsáveis por descrever as características formais do artefato produzido.
Esses dados não são apenas virtualmente infinitos, produzindo uma infinidade de resultados possíveis para uma mesma configuração esquemática, mas também podem incluir variáveis não estáticas e referenciais temporais, que levariam a uma formulação dinâmica e variável do edifício (Lynn, 1999). Deste modo, o design computadorizado propõe a rejeição de soluções rígidas em prol da exploração das potencialidades infinitamente variáveis. Um caminho no qual a forma arquitetônica deixaria de ser uma concepção estática ou inerte, para se tornar conceitualmente uma entidade altamente plástica e mutante, que evolui dinamicamente através de suas transformações interativas (Kolarevic, 2003).

O projeto digital tenta substituir o opaco e subjetivo momento criativo da arquitetura tradicional por um procedimento racional e científico, como quem exime e liberta o arquiteto da autonomia, e da culpa, de decisões projetuais que poderiam ser, em algum momento, consideradas bastante arbitrárias. Entretanto, conforme Jones (1991), o processo de projeto não poderia se tornar um procedimento lógico-racional enquanto não pudesse ser descrito em uma linguagem clara (racional), mesmo que o próprio processo de projeto não seja algo racional.

Por outro lado, ao gerar as diretrizes do esquema paramétrico, todas as possibilidades de concepção já se encontram virtualmente formuladas e definidas, como possibilidades latentes de resolução matemática. Portanto toda a enorme variabilidade de possibilidades fica restrita a um escopo previamente determinado, não havendo espaços para surpresas ou inovações que ultrapassem esses limites.

O processo criativo paramétrico apresenta, de um lado, a formulação de um esquema geométrico, que se mostra fixo e determinado, e, de outro, a escolha dos dados que alimentarão o sistema, que, podem ser considerados tão arbitrários quanto a tradicional definição de "partido arquitetônico" propagada pelos arquitetos do modernismo. A flexibilidade do procedimento paramétrico se ampara na variabilidade de configurações para expressar sua neutralidade, entretanto, na forma final, assumida pelo objeto arquitetônico concretizado, o resultado é singularizado, e o movimento, congelado. A multiplicidade é ofuscada pela cristalização de uma configuração definida pela instância decisória do arquiteto, num movimento contrário à afirmada objetividade neutra e científica da formulação paramétrica. Em última instância, o formfinding se transforma em form-choosing (Cabral Filho, 2013).

\section{PROJETO DIGITAL E PROCESSO DE PROJETO}

Os processos generativos digitais podem ser entendidos como uma experiência exploratória através de procedimentos que são disparados, e adquirem autonomia, para produzir diferentes resultados conforme as diretrizes determinadas. Entretanto, se entendermos que o uso da tecnologia em si não pode ser considerado um modo de fazer arquitetura, tecnicamente, todas as soluções apresentadas como respostas seriam consideradas adequadas, visto que respondem sistematicamente aos parâmetros definidos (Cruz; Eloy, 2012). 
Então, diante da efetiva produção de objetos arquitetônicos, Cruz e Eloy (2012) questionam se a tecnologia digital se apresenta como uma ferramenta que ameaça suplantar o papel criativo do arquiteto, ou se, ao contrário, pode se tornar um trampolim para expandir essa capacidade criativa funcionando como uma ferramenta capaz de conectar a subjetividade cognitiva com a multiplicidade e complexidade das soluções computadorizadas.

Infelizmente esta articulação simbiótica ainda esbarra em algumas restrições processuais, inerentes aos digitais disponíveis atualmente, que acabam distanciando os procedimentos criativos da relação cognitiva direta com a forma em gestação. Assim, a excessiva mediação, que as complexas interfaces digitais aportam ao processo, rompem a relação gestual e tátil disponível na materialidade dos processos tradicionais.

Por outro lado, o caráter exploratório aportado pelo uso de algoritmos, e o foco processual para os procedimentos de geração das formas, não é algo exclusivo das plataformas digitais. Muitos procedimentos metodológicos tradicionais de projeto apostam no enfoque processual e na produção de múltiplas alternativas, definidas por lógicas específicas, para a criação dos artefatos arquitetônicos (Lobosco, 2016).

\section{UM MUNDO PROGRAMADO E SEM MÃOS}

A perda do sentido tátil no projeto digital não deve ser considerada um fenômeno específico, mas uma resposta do campo arquitetônico a uma transformação que ocorre de maneira ampla na sociedade como um todo. Nosso universo parece estar composto, cada vez mais, por nãocoisas: as informações invadem nosso mundo, que se tora desmaterializado no processo de substituição das coisas por imagens, sons e dados "impalpáveis". A transformação parece ainda mais significativa ao entendermos como o homem tradicionalmente manipula seu ambiente, e distingue sua existência no mundo, através desta capacidade de apreender o mundo como um conjunto de coisas, e de o transformar como algo concreto. Essas mãos perdem o sentido diante da tentativa de manipulação um mundo cada vez mais imaterial, visto que as nãocoisas são "inapreensíveis", não há nada a ser tocado ou manipulado, nosso alcance se limita aos seus suportes e meios. O mundo se torna progressivamente mais impalpável, mais nebuloso e aquele que nele quiser se orientar terá de partir desse caráter espectral que lhe é próprio (Flusser, 2007).

A relação com o mundo passa a ser mediada pelas pontas dos dedos, como "órgãos" que são capazes de proferir uma decisão, de fazer uma escolha. Mas a liberdade dessa decisão se torna uma liberdade programada, que escolhe dentre possibilidades prescritas. Assim, a gigantesca multiplicidade de possibilidades previamente definidas e prescritas ofusca a programação e controle das escolhas possíveis. Uma situação que abre um abismo entre programadores e programados, na qual, a autonomia de sua práxis só poderia ser redescoberta na construção de suas próprias ferramentas (Flusser, 2007).

\section{FORM MAKING, FORM FINDING, FORM CHOOSING}

O design parametrizado, se aplicado consistentemente desde a fase de concepção até a materialização arquitetônica, pode alterar profundamente o papel do arquiteto na estrutura hierárquica do processo. Pela primeira vez os arquitetos não estão projetando a configuração (shape) do edifício, mas um conjunto de princípios codificados como uma sequência de operações paramétricas, de modo que as instâncias específicas do projeto podem ser geradas e modificadas a qualquer momento (Kolarevic, 2003).

Associado à transformação da atuação do arquiteto, do form making para o form finding, vemos o surgimento de uma objetificação da arquitetura marcada pela supressão dos valores subjetivos que eram inerentes ao processo de concepção. Em seu lugar, busca-se inserir uma abordagem considerada mais neutra e objetiva, na qual a estrutura criativa se reveste de certo apelo científico, produzindo uma arquitetura objetiva e visualmente espetacular, mas que exclui os usuários finais dos benefícios de uma arquitetura que poderia ser aberta a avançadas formas de interação (Cabral Filho, 2013).

Os parâmetros dinâmicos como movimento, campo de força, variabilidade, interação, etc. atuam como disparadores de possibilidades de relações utilizadas na geração da forma: na tentativa de dar alguma objetividade ao processo, as relações tradicionalmente subjetivas são substituídas por um disparador de possibilidades dentre as quais uma deve ser escolhida para futuro desenvolvimento. Assim, a grande população de variáveis, e o controle sobre a inserção dos parâmetros, busca se distanciar da aleatoriedade e da arbitrariedade que circundam os processos de concepção projetual, através de uma estratégia de form chosing, que chega igualmente rígida e predeterminada ao usuário final.

Neste sentido, Costa Lima (2017) afirma as consequências deletérias de uma cultura global informatizada e desmaterializada, em que a visão prepondera sobre os demais sentidos, na nossa forma de vivenciar apreender e compreender o mundo. Reforçando esta visão, Pallasmaa (2013) e Sennett (2004), destacam a importância de uma relação sensorial, entre mente e mundo, intermediada pela mão, com o propósito de construir uma "consciência material do mundo", um modo de relacionamento espacial e material imprescindível para qualquer ação transformadora da materialidade como a arquitetura. Esses autores nos lembram da importância do tato, mais do que da visão, na compreensão do mundo material: um canal privilegiado de apreensão de informações essenciais e do desenvolvimento das capacidades cognitivas necessárias à transformação criativa do mundo real.

Em arquitetura, uma revelação criativa não é um fato instantâneo, fruto de um processo linear e direto. $O$ resultado é fruto de um processo de amadurecimento que tem idas e voltas, que se ramifica e se cruza (Pallasmaa, 2013). No processo, soluções parciais e detalhes convivem e são testados simultaneamente a proposições e direcionamentos genéricos e é a avaliação permanente e participativa do arquiteto, ao estruturar e reestruturar permanentemente o processo a partir de sua própria inserção, que é capaz de fazer as articulações e conclusões que produzem a proposta final. O projeto não pode ser deixado à sorte de um encaminhamento linear, rígido e previamente elaborado.
3 


\section{GESTO E RELAÇÃO TÁTIL NO PROJETO}

O projeto manipulado é capaz de organizar processos metodológicos que desenvolvem a exploração tátil, abarcando sua dimensão simbólica ao mesmo tempo em que se mantém integrado a uma experimentação formal. A materialidade dos modelos mantém um diálogo permanente com as mãos e com o gesto criativo, ao mesmo tempo em que as diferentes possibilidades de materiais e escalas utilizadas nas maquetes estimulam diferentes relações táteis específicas. Assim, a abordagem material dos modelos no processo de experimentação formal é capaz de gerar igualmente uma significativa variedade de respostas a um mesmo problema. Evidentemente cada solução proposta não é uma resposta automática e instantânea da manipulação das variáveis, mas, em contrapartida, já nasce com uma significativa conexão com atributos simbólicos, tectônicos, históricos, etc.

A tectonicidade construtiva que adquire o material da arquitetura faz parte do atrito que a forma encontra ao se constituir, como um agente ativo, na gênese de seu sentido formal e arquitetônico (Piñón, 1998) e as relações entre materialidade e forma que um modelo físico aporta, são capazes de estruturar uma lógica própria de percepção e formulação arquitetônica.

Evidentemente, esta propriedade material não pretende ser uma simulação da materialidade construtiva do artefato arquitetônico, mas traz ao processo de projeto a lógica tectônica da arquitetura, atuando como um filtro que estimula o gesto e a reação atávica a diferentes respostas cognitivas.

\section{PROJETO TÁTIL}

O desenho à mão, ou a produção de uma maquete física, põe o projetista em contato tátil com o objeto, pois o gesto tátil produz três tipos distintos e simultâneos de imagens: a forma que surge no papel, a consciência de uma intenção criadora da imagem e uma memória muscular do próprio ato de desenhar. Todas são registros de um processo temporal de percepção sucessiva: A fusão entre a mão, os olhos e a mente cria uma imagem única, que não é apenas o registro visual do objeto: o exercício sensorial tátil funde a realidade externa do espaço e da matéria, com a realidade interna da percepção e do pensamento e do imaginário mental em entidades singulares e dialéticas (Pallasmaa, 2013).

A mão cria uma conexão tátil direta entre o objeto, sua representação e a mente do projetista: o gesto do desenho ou a manipulação da maquete ocorrem na mesma espécie de materialidade física que o objeto que está sendo projetado (e que o próprio arquiteto corporifica). Por outro lado, as operações, e o imaginário, de um projeto digitalmente gerado ocorrem no mundo matemático, imaterial e abstrato do computador. Assim, ao criar uma manipulação visual passiva, e promover o rompimento do continuum dialético do processo de projeto, o computador cria uma distância entre o artista e o objeto. O processo passa a ser fragmentado e descontínuo pois a necessidade permanente e inevitável de precisão não permite espaço ao amadurecimento gradativo de ideias e formas. Sem a expressão tátil, o gesto de concepção deixa de ser um pensamento corporificado com ferramentas atuando como extensões e especializações do corpo (Pallasmaa, 2013) para se tornar uma mediação.

\section{NOVOS CAMINHOS}

Entendendo que a concepção arquitetônica deve manter o foco sobre o processo de projetar, e que este processo bem estruturado seria a própria essência do produto desenvolvido, acreditamos que seja possível buscar, nesta forma de atuação, uma conexão direta entre cognição e a materialização da ideia (Sobreira, 2008).

Neste caminho é inevitável reconhecer os ganhos advindos das ferramentas e processos digitais de projeto, não apenas pela capacidade de administrar a complexidade e manipular formas irregulares, mas por sua efetiva capacidade de estimular novos processos e articulações formais. O que questionamos é a excessiva objetificação e abstração que o suporte digital aportou ao processo, promovendo o distanciamento do projetista com a forma do artefato gerado, e um rompimento das relações cognitiva e tátil no processo de projeto.

Afinal, no trabalho criativo, a consciência focada precisa ser momentaneamente relaxada e substituída por um modo de varredura mental corporificado e inconsciente, através de um processo projetual não linear, que alterne escalas e usufrua de uma colaboração continua entre olhos, mãos e mente (Pallasmaa, 2013).

\section{O RESGATE DO GESTO NO PROJETO DIGITAL}

Deste modo, propusemos o desenvolvimento de uma proposta de experimentação projetual livre, visando resgatar os procedimentos gestuais e a materialidade tátil para a construção de uma plataforma digital imersiva e multi-escalar que fosse capaz de integrar os procedimentos tradicionais aos ganhos inerentes às plataformas digitais.

Assim, o primeiro procedimento elaborado para promover o resgate das relações cognitivas e gestuais do projeto foi buscar a interação entre as diferentes ferramentas e interfaces disponíveis. Para isso, a proposta buscou alternar etapas realizadas em suportes materiais e digitais, permitindo ao processo se apropriar da materialidade e da relação tátil dos modelos físicos e, posteriormente, retrabalhar as ideias desenvolvidas através dos suportes digitais e imersivos (Figura 1).

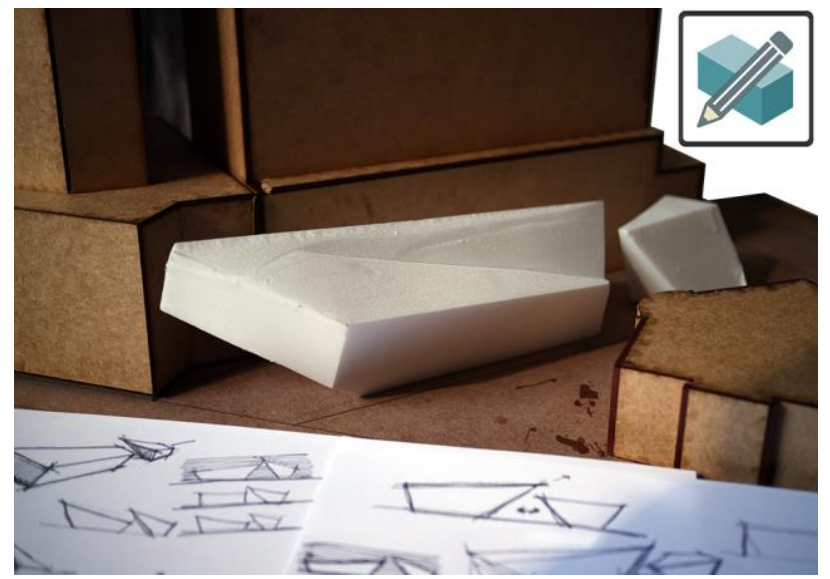

Figura 1: Primeiras experimentações em maquete e croquis. Fonte: Autor. 
Mas apenas a interação entre suportes pouco aportaria para uma verdadeira transformação do modo de projetar digital, pois não promoveria a efetiva reinserção da relação gestual nestes processos, nem o resgate do foco de atuação, dos esquemas abstratos para a forma final do projeto. Neste caminho, o processo de projeto imersivo, através de uma plataforma de realidade virtual, parece ser capaz de suprir a lacuna criada na transição para o digital. Mas, para isso, a RV deve ser capaz de se dissociar da relação de simulação à qual está tradicionalmente associada para se estabelecer como uma ferramenta ativa no processo.

Simulação, ao contrário da virtualidade, não pretende ser um diagrama para uma futura montagem concreta, mas sim um substituto visual. A "realidade virtual" descreve a concepção arquitetônica como um ambiente simulado, e tradicionalmente seria melhor definida como "realidade simulada", visto que o uso do termo virtual se refere a um esquema abstrato que possui a possibilidade de ser atualizado em uma variedade de possíveis configurações (Lynn, 1999), e é exatamente essa característica que nos interessa.
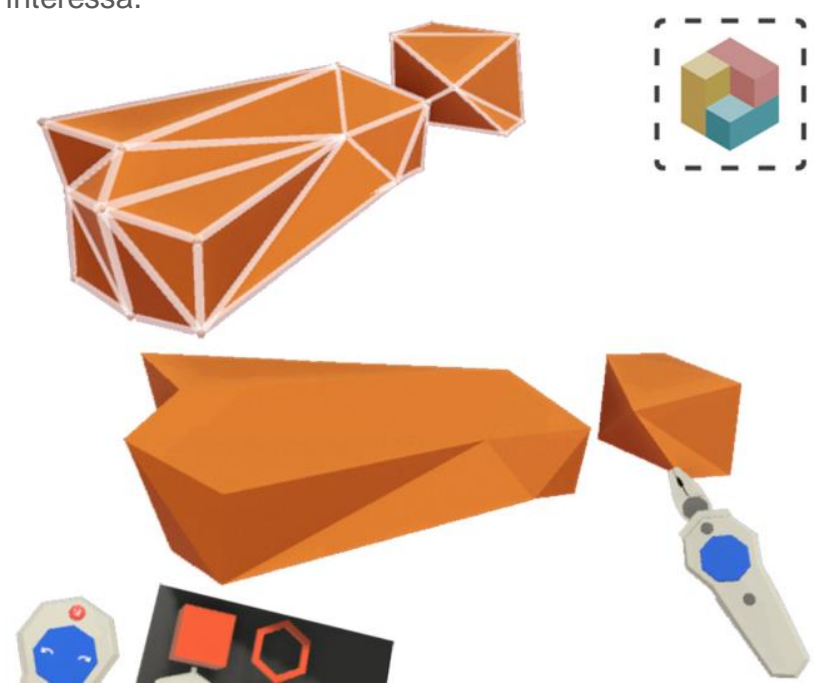

Figura 2: elaboração do primeiro modelo em Realidade Virtual. Fonte: Autor

Assim, demos início à etapa digital e imersiva do processo, através da reconstrução do modelo físico dentro de uma plataforma de realidade virtual HTC Vive, equipada com o software Blocks (Figura 2). Este procedimento buscou resgatar a interação tátil e material do modelo produzido e, ao mesmo tempo, permitir o seu desenvolvimento imersivo e multi-escalar. O software Blocks possui ferramentas de modelagem muito básicas, mas, ao mesmo tempo, uma interface bastante interativa e simples, o que facilita a "sublimação" do aparato técnico que, apesar de todo o procedimento imersivo, ainda se interpõe entre o usuário e o modelo.

Embora inteiramente produzida a partir de suportes digitais, a realidade virtual não se configura como um método generativo semiautônomo, como o design paramétrico, mas tampouco se resume a uma ferramenta representacional, pois não busca simular o processo tradicional de projeto. Sua abordagem principal está conectada às possibilidades de um processo projetual imersivo, e, em decorrência disto: simulado e multi-escalar em tempo real. Deste modo, suas características alteram essencialmente o processo, através de uma interação direta com o mundo simulado que passa a conceber cada elemento tridimensionalmente e dinamicamente localizado no espaço. $O$ projeto em realidade virtual, permite aos utilizadores apreenderem, de modo imediato e em tempo real, muitas características formais e espaciais que não são diretamente perceptíveis no papel ou em projeções perspectivas.

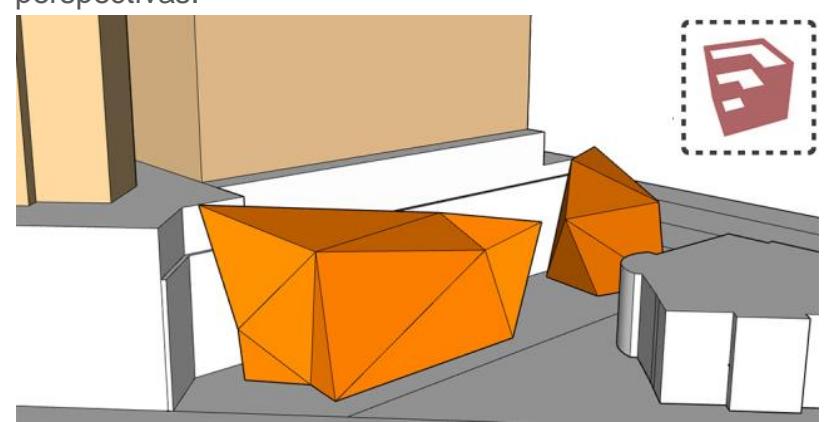

Figura 3: Reelaboração do modelo em SketchUp. Fonte: Autor.

Em seguida exportamos o modelo gerado para ser retrabalhado através no SketchUp (Figura 3). A adoção de uma ferramenta digital não imersiva, permitiu testar a integração dos procedimentos de modelagem tradicionais, além de, por apresentar um melhor referencial escalar, possibilitou recriar o terreno e o entorno onde o projeto se insere, para que estes sejam integrados posteriormente às plataformas imersivas.

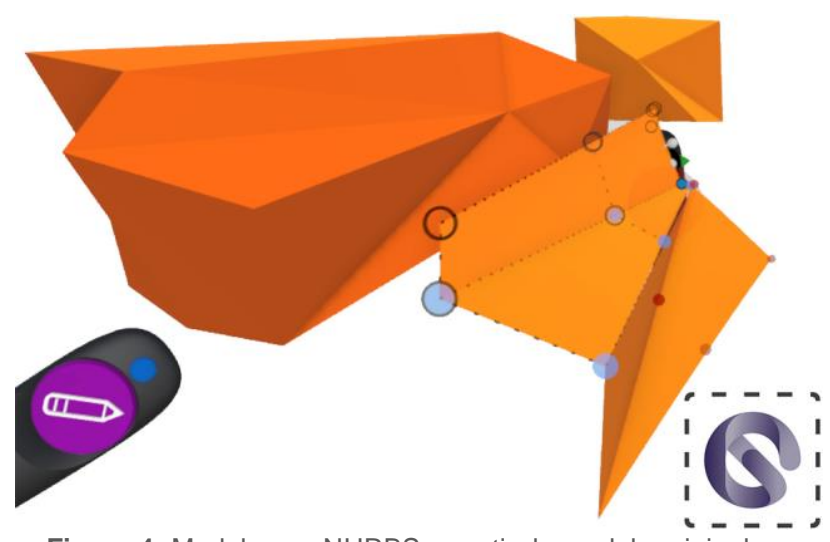

Figura 4: Modelagem NURBS a partir do modelo original, no Gravity Sketch. Fonte: Autor.

O passo seguinte foi a importação dos modelos elaborados para o Gravity Sketch, uma ferramenta de Realidade Virtual que possui ferramentas de modelagem mais complexas como curvas NURBS, permitindo um maior grau de exploração formal dentro do ambiente imersivo (Figura 4).

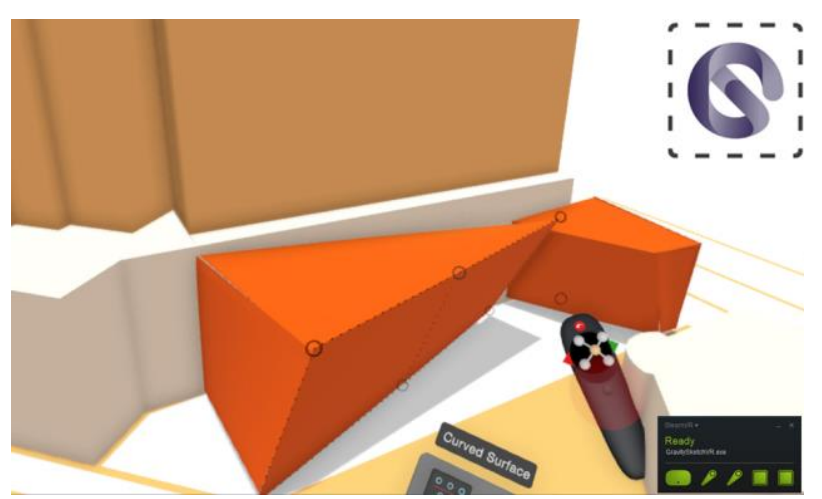

Figura 5: Reelaboração do modelo e entorno, no Gravity Sketch. Fonte: Autor. 
Diferentemente do Blocks, que só permitiu a exportação dos modelos, o Gravity Sketch foi capaz de importar, não apenas modelos criados em outros softwares, como o SketchUp ou o próprio Blocks, mas também a correta e precisa inserção do entorno espacial onde o projeto se insere (Figura 5), permitindo integrar as relações espaciais do entorno na experiência imersiva.

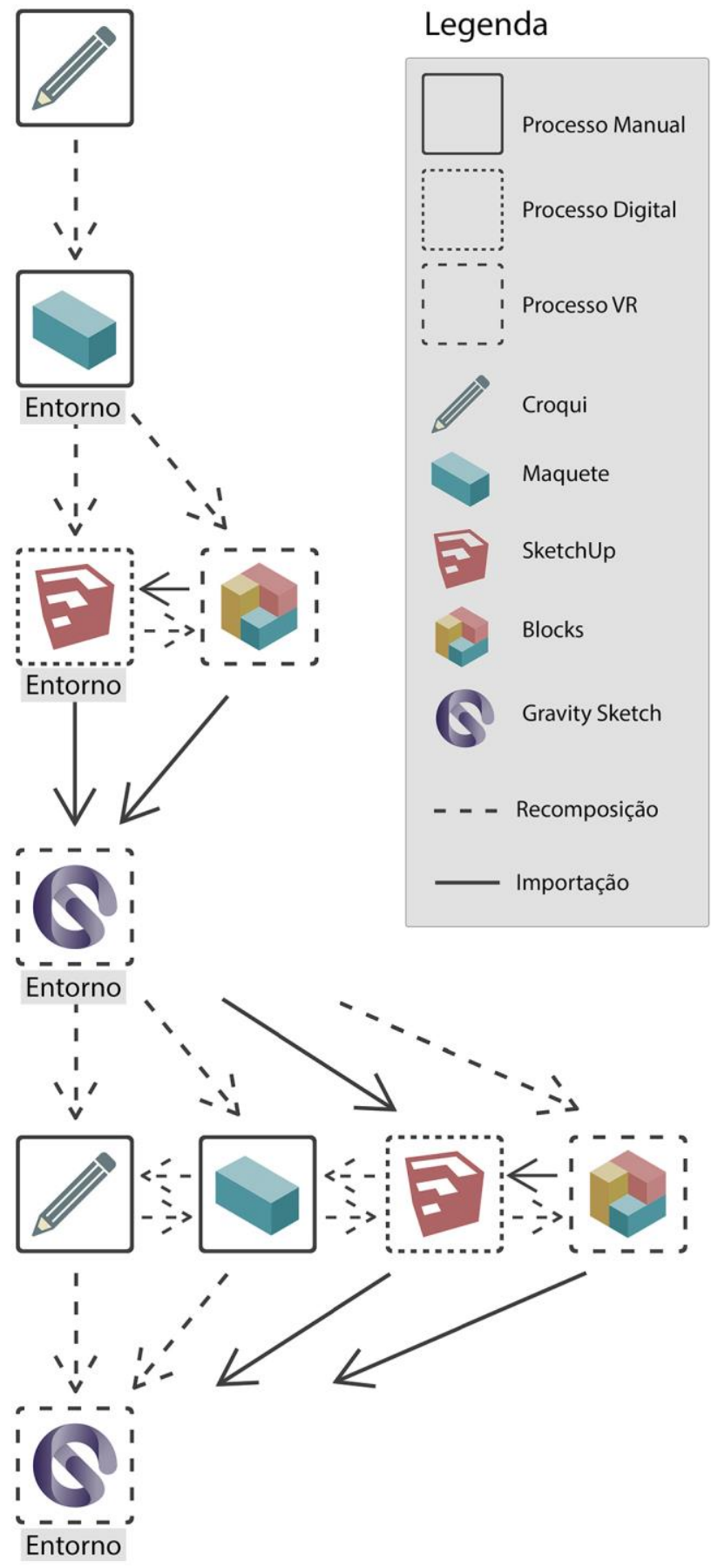

Figura 6: Esquema de interações entre as ferramentas propostas. Fonte: Autor.

Esta situação se mostrou muito promissora, permitindo a aproximação do processo de projeto não apenas com o artefato criado, mas também com as relações espaciais do entorno imediato, que passaram a ser exploradas em ambientes multi-escalares, permitindo alterar, de maneira quase imediata no processo de projeto, entre a percepção do objeto como maquete ou como realidade simulada em escala real.
As etapas experimentadas aqui não se propõem como um sistema linear, mas uma interação aberta na qual diversos processos se intercalam a partir de uma proposta inicial em um suporte manual, buscando-se em seguida maximizar a sobreposição e a interação das ferramentas (Figura 6).

Assim, nos procedimentos adotadas buscamos não apenas importar e transformar os modelos entre as plataformas, mas recriá-los através das novas ferramentas adotadas, assim pudemos experimentar a capacidade construtiva e também identificar a forte influência que cada ferramenta apresentava sobre o modelo gerado.

Estes primeiros movimentos exploratórios nos permitiram identificar o resultado bastante produtivo da interação entre as ferramentas, não apenas pelo aporte das relações táteis e materiais do trabalho em croquis e maquetes, mas também através da sobreposição das inevitáveis influências de cada ferramenta na construção formal.

Entretanto, foi possível identificar que a falta de materialidade dos modelos virtuais produziu uma relação distinta ao manuseio, principalmente diante da falta de resistência oferecida pelos modelos à sua transformação ou manuseio, que restringiram a relação tátil com os artefatos produzidos. Também foi percebida, embora com menor impacto, uma distinta relação com a disponibilidade material, visto que na plataforma digital o material pode se expandir ou contrair infinitamente, alterando os limites tradicionais do trabalho com modelos.

\section{CONSIDERAÇÕES FINAIS}

$\mathrm{Na}$ esteira dos avanços tecnológicos e processuais aportados pelos métodos generativos digitais, o foco do processo foi deslocado da configuração do artefato gerado para um esquema abstrato que manipula dados e não relações cognitivas. Assim, nos procedimentos paramétricos, se torna necessário gerar uma grande diversidade de soluções para que sejam escolhidas as mais adequadas ou pertinentes, pois perdemos, com eles, a capacidade de realimentação contínua dos inputs subjetivos: no projeto tradicional, o resultado é reajustado continuamente através da interpretação imediata do resultado que cada ação produziu no artefato projetado.

A proposta projetual desenvolvida nestes ensaios, demonstrou resultados iniciais bastante satisfatórios no sentido de recuperar as relações gestuais e subjetivas que pareciam ter se perdido na transição digital dos processos de concepção arquitetônica.

A experimentação projetual através de realidade virtual restaurou a interação direta sobre o resultado formal dos artefatos projetados e ainda promoveu a possibilidade de um exercício projetual imersivo, onde o enfoque sobre o processo projetual permanece sendo estimulado, mas a conexão com o resultado final é estruturante da lógica projetual desde seu início. Deste modo, que foi possível perceber uma manifesta evolução na integração entre corpo e ferramenta, apresentada não apenas pela proximidade com 0 artefato projetado, mas também através da exploração multi-escalar. 


\section{REFERÊNCIAS}

Cabral Filho, J. (2013). The ethical implications of automated computation in design. Kybernetes, 42 (9/10),1354-1360.

Costa Lima, H. (2017). O Ateliê Inaugural do Curso de Arquitetura da UNILA: Valiosas Lições da Precariedade. Anais do III Encontro Nacional de Ensino de Estruturas em Escolas de Arquitetura. Ouro Preto: Ed. UFOP.

Eloy, S. Cruz, A. (2012). Será o digital um equívoco na Arquitetura? Arq.urb - USJT (8), 200-209.

Flusser, V. (2007). O mundo codificado: por uma filosofia do design e da comunicação. São Paulo: Cosac Naify.

Jones, C. (1991) Designing, designing. London: Architecture Design and Technology Press.

Kolarevic, B. (2003). Digital Morphogenesis. In Kolarevic, B. (Ed.), Architecture in the Digital Age: Design and Manufacturing (pp.12-28). Londres: Spon Press.

Lobosco, T. Metáfora, analogia e exploração formal no projeto arquitetônico. Projetar 1(3), 27-38.

Lynn, G. (1999). Animate Form. New York: Princeton Architectural Press.
Menges, A. (2006). Instrumental Geometry. Architectural Design, $76(2), 42-53$.

Mitchell, W. (2005). Constructing Complexity. In Proceedings of the Tenth International Conference on Computer Aided Architectural Design Futures, Vienna, Austria, 41-50.

Oxman, R. (2006). Theory and design in the first digital age. Design Studies, 27 (3), 229-265.

Oxman, R. (2008). Digital architecture as a challenge for design pedagogy: theory, knowledge, models and medium. Design Studies, 29 (2), 99-122.

Pallasmaa, J. (2013). As mãos inteligentes. Porto Alegre: Bookman.

Piñón, H. (1998). Curso Básico de Proyectos. Barcelona: Edicions UPC.

Sennett, R. (2004), The Craftsman. London: Penguin.

Sobreira, F. A desconstrução do princípio: Ensaio sobre o ensino do projeto de arquitetura. Arquitextos 8 (95-05). 2008. Disponível em: <http://www.vitruvius.com.br/revistas/read/ arquitextos/08.095/151>. 